\title{
WeChat and Ideological and Political Education of College Students
}

\author{
Yu Zhao, and Qiang Shen*
}

Graduate School of Jilin Agricultural University, Changchun, Jilin, 130118;

School of Marxism, Jilin Agricultural University, Changchun, Jilin, 130118

a511570425@qq.com, bjlshenqiang@126.com

Keywords: WeChat; College students' growth; Ldeological and political education

\begin{abstract}
WeChat, as new media software, has been widely accepted and universally applied among college students. During the process of using WeChat, college students' world outlook, outlook on life and value have been changed imperceptibly with profound impact on their behaviors and ideology and morality. This paper studies the impact of WeChat on college students through questionnaires and proposes some methods of fully utilizing WeChat's influence to conduct the ideological and political education.
\end{abstract}

\section{Basic Introduction to WeChat}

Imperceptibly, when we reflect on our own, what is the thing that we cannot ignore every day? After searching our hearts, the answer to the question is really a bit unbelievable. It is not our relatives and parents who have bloodline with us nor our close friends, but a small mobile phone software WeChat. This is not the opinion of a single person, but there are a lot of data in front of us: the popularity of WeChat has exceeded any other previous fashion. Nowadays, of someone has not yet had a WeChat account or belong to a WeChat group, he/she seems to be an ancient people who will not only be laughed by friends, but also cannot keep up with the rhythm of their talks. Investigations show that $55.2 \%$ users have opened their WeChat account for more than 10 times every day, and $25 \%$ users open it for more than 30 times every day. Now, for more and more people, WeChat becomes their first morning greeting, all-day accompany and daily good night greeting. WeChat has opened a new way of life with about 570 million people opening their WeChat account everyday while in first-tier cities like Beijing and Shanghai, WeChat's penetration rate has even reached $93 \%$. It can be said that everywhere you can see and contact is surrounded by WeChat.

WeChat is mainly used to spread news, record personal feelings in life and show travelling, gourmet, photos, happiness, privacy, inspiration, philosophy, life enlightenment, health knowledge, practical knowledge, holiday wishes, chatting, daily communication and exchanges, etc. This makes WeChat users have the feeling of living in a courtyard. They enjoy the convenience of daily life, share their happiness and sorrows, communicate with each other anywhere and at any time and release their emotions when they are boring at WeChat. Therefore, WeChat is a lifestyle that clearly demonstrates the lives of numerous users. In this regard, some people are willing to "enjoy" it and some people are irresistibly "wrapped" in it, so it seems that a major trend "evolve in WeChat or lag behind in WeChat" has been virtually formed.

In the contemporary Chinese society, even neighbors living next door do not know each other, and everyone does not have the sense of belongingness with far mutual psychological distance. However, WeChat makes up for this and solves urban people's problem of lacking interpersonal communication, satisfying people's demand for belongingness, i.e. the demand for being accepted by a certain group. Various WeChat groups have provided a platform for people to increase their social exchanges, enhance mutual understanding, mutual acceptance and mutual recognition, and created an atmosphere beneficial for interpersonal relationship to meet people's demand for affiliation. People register their WeChat accounts and use WeChat for various purposes, but in general, they want to keep up with the trend. Some people use WeChat to help others and provide information and convenience for other, such as helping others seek their relatives and trafficked children. Through WeChat, people can not 
only communicate with each other and send messages at any time, but also "show" everything they want.

\section{WeChat's Impact on College Students}

In order to get to know the real situation of college students' usage of WeChat, this paper takes students from a college in Changchun as the investigation sample to get to know the current situation of WeChat's impact on the behaviors and thoughts of college students in this area. This paper mainly adopts the method of combining questionnaire survey with individual interviews. The questionnaire survey was conducted in December 2015 by distributing 160 "Investigation of College Students' Usage of WeChat" questionnaires to 4 classes at different grades and of different disciplines. Finally, 152 valid questionnaires and 8 invalid questionnaires have been gathered with the valid recovery rate being at $95 \%$. Meanwhile, 4 students who use WeChat were interviewed to investigate the basic situation and contents of their usage of WeChat.

Positive Impact. Firstly, WeChat is an important means for college students to obtain information, and they can obtain relevant information from the moments, public WeChat account, Tencent news, micro-blog reading, etc. According to survey, $10 \%$ students use WeChat to send videos and pictures, and 5\% students use WeChat to send emails and for microblogging. Students can pay attention to their students, friends or celebrities they like on moments, and timely read their information sent in their moments. Many students release their own status, such as mood or feelings on moments to share with their friends their recent news as well as get to know their friends' recent news at the same time. Moments can be used to record and share user experience. "Through sharing, users' relationship is expanded from offline to online, which consolidates and enriches users' contact". Public WeChat account is the application account of developers or companies on the public WeChat platform. Companies can communicate and interact with a specific group on the WeChat platform in an all-round way through texts, pictures, voice and videos, and college students can obtain information by paying attention to relevant public WeChat account. On micro-blog reading, users can read papers recommended by their friends and get to know what their friends are concerned about. Tencent news will publish daily domestic and international news so that users can timely get to know the latest social issues.

Secondly, WeChat can promote communication between friends and classmates. (1) WeChat can help save text message, calls and traffic. According to investigation, 28\% students use WeChat because WeChat can help save costs in message and calls. After using WeChat, 7\% students' costs on calls have been increased, $16 \%$ students' costs on calls have been decreased, and there is no change to $77 \%$ students. This indicates that as long as the application is reasonable, WeChat can save costs. (2) Students register their WeChat accounts in order to communicate with their friends and classmates. According to investigation, $42 \%$ students use WeChat because their friends use it, and $57 \%$ students use WeChat mainly to communicate with their existing friends. From the investigation into the source of WeChat friends, 53\% students have their WeChat friends from their QQ friends, 44\% students have their WeChat friends from their mobile phone contacts and 7\% students have their WeChat friends from friends' recommendation. 7\% students believe that WeChat can make their interpersonal relationship closer to a great extent, and $31 \%$ students believe that WeChat can make their interpersonal relationship closer to a limited extent. This shows that a lot of students use WeChat to promote their interpersonal relationship. (3) WeChat's voice chat function can facilitate communication with classmates and friends because it is easier to talk through voice and enhance friendship, and it is also more interesting to talk in voice than just sending text message. Besides, there is also real-time intercom and video chat on WeChat. According to investigation, $69 \%$ students use WeChat mainly for text and voice chat.

Thirdly, WeChat can help students expand their circle of communication. According to investigation, $37 \%$ students will use the drift bottles on WeChat to seek friends occasionally in the evening or after 12 O'clock at night, $32 \%$ students mainly use the "Shake" or "drift bottles" on 
WeChat, and 7\% students have their WeChat friends from "Shake", "drift bottles" or "nearby people". $28 \%$ students use WeChat because they can get to know nearby friends, $37 \%$ students use WeChat to communicate with strangers, and $24 \%$ students will tell strangers on WeChat their own inner feelings. WeChat shake, drift bottle and nearby people are new ways to get acquainted with strangers, so students can use them to expand their circle of communication.

Fourthly, WeChat can add fun to college life. In terms of the time to register and use WeChat, 20\% students use WeChat during class sessions, $13 \%$ students use WeChat at noon breaks, $60 \%$ students use WeChat before sleep, 31\% students use WeChat because they are curious about it, and 30\% students use WeChat in order to kill time. This shows that students are happy to use WeChat during their spare time to add fun to life. For instance, the "Shake", "drift bottle" and "nearby people" on WeChat satisfy students' demand for freshness and curiosity. WeChat game center promotes the most popular games at present. They are convenient and adds fun.

Negative Impact. Firstly, most students believe that it is a waste of time to use WeChat. According to investigation, $8 \%$ students use WeChat at class, so it will obviously affect their study. $12 \%$ students are on WeChat for more than 4 hours, which will undoubtedly distract their attention. In terms of the disadvantages of using WeChat, most students think that its great disadvantage is to waste time and distract attention. Some students point out that using WeChat can waste their network flow because they have to shake every day, thus prolonging their time on the mobile phones and affecting their relaxation.

Secondly, a small number of students will become addicted to WeChat and WeChataholic, which means they are extremely fond of using WeChat with the WeChat complex. As has been pointed out by some netizens that "On WeChat, you can only believe in it a little", but a lot of college students are extremely addicted to WeChat. From the survey, $76 \%$ of the students on the line every day for 0 to 2 hours on the line, indicating that students use WeChat more rational. However, 6 of the students online $6 \%$ hours per day, $6 \%$ of the students online 4 to 6 hours per day. This shows that $12 \%$ of the students are fascinated by WeChat, there is a certain degree of addiction, is the formation of WeChat's performance. Current college students are after 90, they "rely on strong, self-adjustment ability is poor, real communication ability is not strong, their excessive dependence on micro channel will cause itself mired in the micro channel to create a virtual social interaction, forming lonely autistic social character." These WeChat addicted students are the focus of teacher education and guidance, not only to their learning content to strengthen counseling, but also to their personality growth and mental health.

Thirdly, WeChat is easy to carry out criminal activities by criminals. WeChat "nearby" function is through the LBS positioning function to find the distance of 1000 meters in the use of WeChat, a shake function can find the same time together with your mobile phone shake people. The two function of WeChat has been favored by many young people. On the one hand, these functions as the strangers provides a convenient and efficient to meet and exchange platform, on the other hand also give criminals an opportunity to exploit. The WeChat crime incident. 2012 December 9, the central television station "focal interview" program on the micro channel related cases reported, titled "Don't let WeChat become credit crisis", reveals the micro channel network security problems, a lot of people have been swindled, cheating the color or even lose their lives. For college students to use micro letter to protect personal information consciousness is not strong, in investigating whether in micro channel fill in real personal information and upload your own photos, $15 \%$ of the students choose "absolutely not", 39\% of students choose to "may", 29\% of the students chose "occasionally", $17 \%$ of the students choose "not really". This shows that a part of the students once gave their own information on their WeChat account.

\section{Fully Utilize WeChat to Carry out Ideological and Political Education to College Students}

The key of conducting ideological and political education to college students is to keep pace with time, so it is necessary to use WeChat as the carrier because it can effectively assist in conducting 
ideological and political education.

The establishment of Ideological and political education of WeChat public information platform. College Students' Ideological and political education needs to continuously develop new positions, enhance their attractiveness, and ensure the dominant position of students and guide. Therefore, our ideological and political education should be quickly cut into the WeChat carrier, WeChat brings challenges into opportunities. The establishment of schools, classes, and other branches of WeChat public platform, encourage teachers to use WeChat to achieve timely information exchange and feedback, to understand and grasp the students' thoughts, build the information resources sharing platform.

Use the hot recommended functions of WeChat and carry out interaction with students through real educational activities according to popular social issues of students' concern. Such as: Voice intercom function can be promptly issued a notice, organize collective activities; micro "shake" and "drift bottles" function, the content of Ideological and political education then sent; another example is the "snapshots" function, to enable students to actively participate in the campus cultural construction, increase the sense of participation, improve the management of students' self-education and enthusiasm.

To sum up, the upcoming of the "WeChat era" as well as the rapid development and new situation of new media call for the cooperation and endeavor of the government, communication media and each other parties. Only when each group and individual in the society can improve their knowledge and have the awareness of unexpected development as well as strive to maintain the equal and orderly sharing of social information, can a society dominated by learning and keeping pace with the time come, and the increasing knowledge gap in China can be effectively improved.

\section{References}

[1] Anderman, L., \& Anderman, E. 1999. Social Predictors of Changes in Students' Achievement Goal Orientation. Contemporary Educational Psychology, 24 (1), 21-37.

[2] Fleith, D. 2000.Teacher and Student Perceptions of Creativity in the Classroom Environment. RoeperReview,22(3), 148-153.

[3] Carrell, J.B. 1993. Human Cognitive Abilities. New York: Cambridge.

[4] Hymes, D. 1972. On Communicative Competence [A].In J. B. Pride (eds). Social linguistics [C].Harmondsworth: Penguin.

[5] Berwick, R. Towards an Educational Framework for Teacher-led Tasks [M]. Avon: Multilingual Matters, 1993.

[6] Thornbury, S. Uncovering Grammar.[M]. London:Macmillan ELT, 2003.

[7] Krashen. The Input Hypothesis: Issue and Implications [M]. London: Longman.1985.

[8] Vygotsky, L. Mind in Society: The Development of Higher Psychological Processes, Cambridge:Harvard University Press.1978

[9] NCSSFL-ACTFL. (2012). Can-Do Statements. Alexandira: ACTFL

[10] Skehan, P. (2014). Processing Prospectives on Task Performance. Amsterdam: John BenjaminsPublishingCo. 